\title{
Effects of Functional Electrical Stimulation Intensity Level on Corticomuscular Coherence during Action Observation
}

\author{
Ji Young Kim¹, Hyunju Noh², Jiwon Park \\ 'Department of Physical Therapy, Masan University, Masan, Republic of Korea; ${ }^{2}$ Department of Nursing, Cheju halla University, Jeju, Republic of \\ Korea; ${ }^{3}$ Department of Physical Therapy, College of Bio and Medical Science, Daegu Catholic University, Gyeongsan, Republic of Korea
}

Purpose: This study examined the effects of changes in the intensity of Functional Electrical Stimulation (FES) on CorticoMuscular Coherence (CMC) during action observation. This paper presents a neurophysiological basis for the effective intensity of FES.

Methods: Twenty-seven healthy volunteers were asked to observed a video with FES. The FES was provided with a sensory stimulation level, nerve stimulation level, and motor stimulation level. Simultaneously, an electroencephalogram (EEG) of the sensorimotor cortex and electromyogram (EMG) from the wrist extensor muscle were recorded. The peak $\mathrm{CMC}$ and average $\mathrm{CMC}$ were analyzed to compare the differences caused by the FES intensity.

Results: The peak CMC showed a significant increase in the alpha band during motor stimulation $(p<0.05)$. The average CMC showed a significant increase in the beta band during motor stimulation $(p<0.05)$.

Conclusion: The intensity of FES, which causes actual movement, increased the CMC during action observation. These results show that the intensity of the FES can affect the functional connection between the sensorimotor cortex and muscle.

Keywords: Observation, Electric stimulation therapy, Coherence

\section{서 론}

최근에는 뇌파의 변화뿐만 아니라 근육 움직임과의 동기화를 이용 한 상관성 연구가 진행되고 있고, ${ }^{1-3}$ 이와 관련된 전기생리학적인 변 화는 Electroencephalogram (EEG)와 Electromyogram (EMG)를 이용 하여 중추 및 말초신경시스템의 활성 정도(level)로 연구되어 질 수 있 다. 실제적 움직임 혹은 움직임 관련 감각입력 증가는 일차운동겉질 (primary motor cortex) 및 감각운동겉질(sensory motor cortex)의 진동 변화를 유발시킨다. ${ }^{2}$ 자발적 움직임의 발생은 대뇌(cerebrum)가 해당 근육에 대한 수축을 지시한 결과로, 대뇌겉질의 율동적 진동 활동과 동시에 근육의 활성에 영향을 미치게 된다. ${ }^{3}$

겉질근육코히런스(CorticoMuscularCoherence, $\mathrm{CMC}$ )는 EEG와 $\mathrm{EMG}$ 사이의 주파수 율동 동기화(synchronization)현상이다. ${ }^{4.5} \mathrm{CMC}$ 는 두 신호 사이의 선형관계로 측정되는데, ${ }^{2}$ 주파수 대역을 중심으로 두 파형의 상호 관련성을 나타내는 0 에서 1 사이의 지수로 표시된다. ${ }^{6}$ $\mathrm{CMC}$ 의 크기는 진폭(ampulitude)이 아닌 진폭 사이의 비율에 의해 계
산되어 결정되어진다. 비록 $\mathrm{CMC}$ 의 생리학적인 기전이 명확하지 않 더라도, 대뇌에서 발생된 진동이 겉질척수로(corticospinal tract)의 축 삭(axon)을 거쳐 직접적으로 운동신경원(motor neuron)으로 전파되 는 것을 근거로 하여 대뇌와 근육사이의 소통을 반영하는 것으로 널 리 받아들여지고 있고, ${ }^{3,4}$ 이들 사이의 기능적 연결을 평가하기 위한 수단으로 활용되고 있다. ${ }^{1} \mathrm{CMC}$ 가 해당 뇌 영역과 척수 사이의 편심 성(efferent) 연결에 의해서만 나타나는 것은 아니다. ${ }^{8}$ 대뇌겉질과 척수 사이의 정보흐름 방향에 관한 연구에서는 양측성 전달이 존재한다 고 보고되고 있고, ${ }^{8}$ 효율적으로 말초 시스템에 대한 감각운동 모니터 링을 하는 것과 관련이 있는 것으로 추측되고 있다. ${ }^{4}$

외상성 뇌손상 환자 및 뇌졸중 환자는 운동조절과 관련된 신경네 트워크 차단으로 인해 중추신경계와 말초신경계사이의 소통장애가 발생하고 이는 운동장애로 연결된다.' 지금까지 많은 분야에서 신경 가소성을 증가시키고 대상자의 기능적 독립수준을 향상시키기 위한 운동신경 및 감각신경과 감각자극을 활용한 인지적 재활 훈련들이 진행되어 오고 있다. 특히 동작 실행시와 동일한 운동사슬의 신경회 
로 흥분을 유발하여 관련된 뇌 영역의 잠재적 활성을 만들어 낼 수 있는 동작관찰(action observation)과 관련된 연구가 활발히 진행되고 있다.9-11

기능적전기자극(Functional Electrical Stimulation, FES)은 근육과 신 경을 자극하여 수축을 유발시키는 치료적 장비로써, 중추신경계 손상 환자의 기능 회복을 위한 중재적 방법으로 활용되고 있다. ${ }^{13-15}$ 최근에 는 $\mathrm{EEG}$ 분석을 통해 $\mathrm{FES}$ 가 감각운동겉질의 활성 변화를 유발하는 것 으로 보고되고 있고, 뇌가소성 증진을 위한 근거로 제시되고 있다.16,17

$\mathrm{FES}$ 가 가진 인지적 측면을 보완하기 위해 동작관찰과 함께 $\mathrm{FES}$ 를 제공하여 뇌졸중 환자의 기능회복 효과를 비교 분석한 연구, ${ }^{18}$ 감각 운동피질의 활성변화를 분석한 연구도 진행되고 있다. ${ }^{17}$ 그러나, 동작 관찰의 변이에 따른 뇌활성의 변화와 관련된 다양한 연구 결과가 보 고되고 있음에도 불구하고, ${ }^{19-21} \mathrm{FES}$ 의 강도 변이와 관련된 신경생리 학적인 연구는 미흡한 실정이다. 또한 뇌와 근육 사이의 기능적연결 을 평가하는 도구인 $\mathrm{CMC}$ 를 통해 신경생리학적인 변화를 보고한 연 구도 부족한 상태이다. 이에 본 연구에서는 동작관찰 동안 제공되는 $\mathrm{FES}$ 의 강도에 의해 나타나는 변화를 $\mathrm{CMC}$ 를 통해 비교분석하고, 효 율적인 FES의 적용강도에 대한 신경생리학적인 근거를 제시하고자 하였다.

\section{연구 방법}

\section{1. 연구대상}

본 연구는 건강한 $20 / 30$ 대(평균 $25 \pm 3$ ) 성인 27명을 대상으로 하였다. 모든 대상자는 오른손잡이인 자, 정상이거나 정상으로 교정된 시력 을 지닌 자, 신경학적 질환의 병력이 없는 건강한 자로 제한되었다. 또 한 연구의 목적 등에 관한 구체적 설명을 들은 이후에 자발적으로 참 여하였다.

\section{2. 실험방법}

1) 표면근전도

본 연구에서는 Delsys Triagno Wireless EMG system (Delsys Inc., Boston, MA, USA)을 사용하여 근전도 신호를 획득하였다. 피부 저항을 최소화하기 위해 아래팔을 의료용 알코올로 깨끗이 닦아낸 후 전극 을 부착하였다. 전극이 부착된 위치는 손목관절 폄근의 근복(muscle belly)으로부터 $2 \mathrm{~cm}$ 떨어진 몸쪽(proximal part)이며 근육섬유의 주행 방향에 평행하게 부착하였다. 표본추출률(sampling rate) 2,000 Hz로 획득된 아날로그 신호는 Delsys EMG Works Acquisition 소프트웨어 를 이용하여 Remove mean, band pass filter (2-500 Hz), Resampled (200 $\mathrm{Hz}$ ) 과정을 거쳐 디지털 신호로 변환된 다음 분석을 위해 컴퓨터에 파일로 저장되었다. 1,000 개의 데이터가 매 5 초단위로 수집되었고, 총
60-70개의 segment를 분석에 사용하였다.

\section{2) 기능적전기자극기}

기능적전기자극기 Microstim (MedelGmBH, Berlin, Germany)는 손목 관절 폄근에 적용되었다. 2 개의 전극은 이극배치법(bipolar placement) 으로 부착되었고 맥동기간 $300 \mu \mathrm{s}$, 자극주파수 $30 \mathrm{~Hz}$, 위상성 지속 전 류(biphasic constant current)로 설정하여 되었다. 감각수준의 자극을 제공하는 동안에는 대상자가 느끼는 최소한의 자극 강도보다 2-3배 높게 설정 $(2-6 \mathrm{~mA})$ 하여 제공하였고, 신경수준의 자극을 하는 동안에 는 손목관절 폄근의 수축에 의해 움직임이 유발되는 최소한의 강도 보다 $10 \%$ 낮게 설정 $(8-14 \mathrm{~mA})$ 하여 가시적 근수축이 유발되지 않는 강 도로 설정하였다. 운동수준의 자극은 대상자가 불쾌감을 느끼지 않 으면서 손목관절의 폄이 실제 움직임의 각도와 비슷하게 유발되는 강도 $(12-20 \mathrm{~mA}$ )로 제공하였다.22,23 각 자극은 통전시간 5초, 경사증가 및 감소시간각 1 초로 총 7 초 동안 지속되었다.

\section{3) 뇌파측정기}

24채널 전산화 무선뇌파측정기 Neurofax EEG-1200 (Nihonkhoden corprtation, Tokyo, Japan)를 이용하였다. 전극은 국제 10-20 전극 시스 템(international 10-20 electrode system)'에 따라 부착되었고, C3를 활성 전극으로 한 AV delete 전극유도를 통해 전위의 차이가 계산되었다. ${ }^{24}$ 샘플링 주파수는 $200 \mathrm{~Hz}$, 민감도(sensitivity) $10 \mu \mathrm{V}$, 시간상수(time constant) 0.3 초, 고주파 여과 $60 \mathrm{~Hz}$, 저항은 $10 \mathrm{k} \Omega$ 이하로 유지 시켰고, 눈 깜박임 및 안구의 움직임에 의한 잡파의 혼입은 앞쪽에 위치한 EEG 채널(Fpl, Fp2)을 이용해 제거되었다. 획득된 원(raw)데이터는 매 7초 동안의 자극 중 제시된 시점에 대해 처음 1 초와 마지막 1 초를 제외한 5 초 단위로 추출되어 분석에 이용되었다.

\section{4) 동작관찰영상}

대상자의 $1 \mathrm{~m}$ 앞에 높인 27인치 모니터에서 동작관찰영상이 제공되 었다. 전방에 위치한 컵을 잡는 손 동작이 7초 동안 재생되었고, 모든 대상자들은 동일한 영상을 총 35 회 반복적으로 제공받았다.

\section{3. 실험절차}

모든 대상자들은 조명이 어두운 조용한 방(room)에 들어가 적응시 간을 가지면서 실험에 대한 설명을 들었다. 등(back)을 의자에 기대고 앉아 가장 편안한 자세를 취한 후, 책상에 팔을 올려놓고 실험이 진행 되는 동안에는 움직이지 않을 것을 지시 받았다. FES와 동작관찰이 동시에 제공되는 동안 $\mathrm{EEG}$ 와 $\mathrm{EMG}$ 가 측정되었고, $\mathrm{FES}$ 강도 변이에 따라 반복적으로 측정 받았다. 자극 강도 조절에 의해 감각수준의 자극, 신경수준의 자극, 운동수준의 자극으로 총 3 session이 진행되 
었고, 각 session당 5 회 반복 자극됨에 따라 총 15 회의 시도가 이루어 졌다. 대상자의 피로를 방지하기 위해 각 session 사이에는 60초 가량 의 휴식이 제공되었고, 순서에 의한 효과를 배제하기 위해 무선배치 되어 진행되었다.

\section{4. 자료분석}

$\mathrm{CMC}$ 를 계산하기 위해 동시적으로 측정된 $\mathrm{EEG}$ 의 원데이터와 정류 화된 $\mathrm{EMG}$ 신호를 사용하였다. 본 연구에서는 전체 윈도우 중 각 7초 동안의 자극에 대하여 매 5 초 간격으로 잘라서 데이터를 사용하였으 며, 수집된 각 1,000 개의 데이터는 MATLAB soft-ware (The MathWorks, US)를 사용하여 분석하였다.

$$
\operatorname{coh} x y(f)=|R x y(f)|^{2}=\frac{|P x y(f)|^{2}}{P x x(f) P y y(f)}
$$

cohxy는 코히런스 값으로, Pxy는 EEG 신호(x)와 정류화된 EMG 신 호(y)의 크로스 스펙트럼 값이고, Pxx와 Pyy는 동일한 주파수 영역에 서 두 신호 각각의 스펙트럼 값이다. ${ }^{25}$ 코히런스의 값이 유의미하기 위 해서는 신뢰수준(confidence level, CL)을 만족해야 하고, ${ }^{26}$ 계산된 CL 은 0.0306 이었다. 이 수준을 넘는 값만이 통계적 분석에 사용되었다. $a$ 는 유의수준 $95 \%$ 를 의미하고, $\mathrm{L}$ 은 스펙트럼에 사용된 주파수의 수를 의미한다.

$$
C L(\alpha=0.95)=\frac{1-(1-\alpha) 1}{(L-1)}
$$

분석은 8-13 Hz의 알파밴드, $14-30 \mathrm{~Hz}$ 의 베타밴드, 그리고 $31-50 \mathrm{~Hz}$ 의 감마밴드로 나누어 진행되었고, 통계적 분석에 앞서 가우시안 분 포를 만들기 위해 코히런스의 제곱근에 Fisher의 Z변환을 적용하였 다. $\mathrm{FES}$ 강도에 의한 각 주파수 대역별 $\mathrm{CMC}$ 값차이를 분석하기 위해 분산분석을 실시하였고, 사후검정은 bonferroni를 이용하였다. 통계
학적 유의수준 $\mathrm{p}$ 는 0.05 로 정하였다.

\section{결 과}

동작관찰과 동시에 $\mathrm{FES}$ 를 제공하는 동안 자극강도의 차이에 따른 각 대역별 $\mathrm{CMC}$ 값의 통계적 차이를 알아보기 위해 average $\mathrm{CMC}$ 를 분산분석 하였다. 그 결과 베타 $\mathrm{CMC}$ 에서 유의한 차이를 나타내었고 ( $<<0.05$ )(Table 1), bonferroni방법을 이용한 사후검정결과 감각자극 수준과 신경자극수준에 비해 운동자극수준에서 유의한 증가가 나 타났다. CMC에 따른 결과를 다음과 같다(Figure 1).

\section{고 찰}

본 연구에서는 동작관찰 동안 제공되는 $\mathrm{FES}$ 의 강도에 의해 나타나

Table 1. Comparison of each band average CMC according to FES intensity

$(\mathrm{N}=27)$

\begin{tabular}{lccccc}
\hline & Condition & Average coh & F & p & Post-hoc \\
\hline Alpha & SSL (a) & $0.01 \pm 0.01$ & 3.735 & 0.090 & \\
& NSL (b) & $0.01 \pm 0.01$ & & & \\
\multirow{4}{*}{ Beta } & MSL (c) & $0.01 \pm 0.01$ & & & \\
& SSL (a) & $0.02 \pm 0.01$ & 5.645 & $0.019^{*}$ & $\mathrm{a}, \mathrm{b} / \mathrm{c}$ \\
& NSL (b) & $0.02 \pm 0.02$ & & & \\
gamma & MSL (c) & $0.03 \pm 0.02$ & & & \\
& SSL (a) & $0.07 \pm 0.04$ & 1.622 & 0.334 & \\
& NSL (b) & $0.06 \pm 0.03$ & & & \\
& MSL (c) & $0.06 \pm 0.03$ & & & \\
\hline
\end{tabular}

mean \pm standard deviation, SSL: sensory stimulus level, NSL: nerve stimulus level, MSL: motor stimulus level.

${ }^{*} p<0.05$.
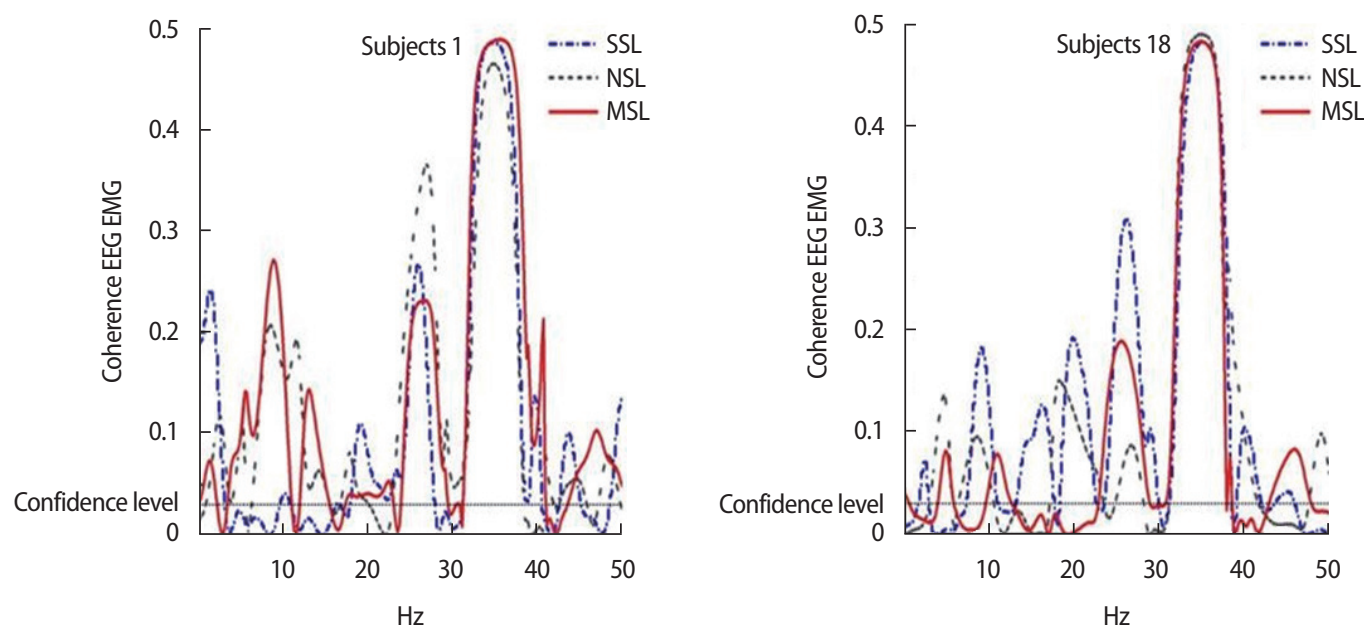

Figure 1. Changes of each band CMC according to FES intensity. SSL: sensory stimulus level, NSL: nerve stimulus level, MSL: motor stimulus level. 
는 변화를 $\mathrm{CMC}$ 를 통해 비교분석하고, 효율적인 FES의 적용강도에 대한 신경생리학적인 근거를 제시하고자 실시되었다. 그 결과 베타밴 드 대역에서 average $\mathrm{CMC}$ 가 감각자극수준과 신경자극수준에 비해 운동자극수준에서 유의하게 증가하는 것으로 나타났다 $(\mathrm{p}<0.05)$. 이 는 실제적 움직임을 유발하는 수준의 FES 강도가 동작관찰을 하는 동안 가장 효과적으로 뇌와 근육 사이의 연결을 강화시킬 수 있다는 것을 보여주는 결과라고 추측된다.

$\mathrm{CMC}$ 의 강도는 여러요인들에 의해 영향을 받는다고 알려져있다. Ushiyama 등 6 , 그리고 Divekar와 John ${ }^{4}$ 은 대뇌에서부터 운동신경원을 거쳐 근육으로 가는 신경투사(projection)가 많을수록 CMC가 증가 한다고 하였고, Schoffelen 등8은 말초에서 발생한 발생한 동심성(afferent) 신호의 입력 증가가CMC 강도 증가에 기여한다고 하였다. Yang 등 ${ }^{3}$ 과 Muthukumaraswamy ${ }^{5}$ 은 $\mathrm{CMC}$ 의 강도가 운동과제에 특이적으 로 의존되어 등척성으로 정적인 힘을 생산하는 동안에는 $20 \mathrm{~Hz}$ 대역 에서 증가하고, 같은 수준의 힘을 동적으로 생산해 낼 때에는 $40 \mathrm{~Hz}$ 대역에서 증가하여 나타났다고 보고하였고, McClelland 등 ${ }^{2}$ 은 중등 도 이하의 등척성 수축을 유지하는 동안에는 $15-35 \mathrm{~Hz}$ 대역에서 $\mathrm{CMC}$ 가 우세하게 나타나게 되고, 강한 수축을 유지하는 동안에는 $30-50 \mathrm{~Hz}$ 대역에서 코히런스가 증가하여 나타난다고 하며 CMC의 강 도는 발생되는 힘의 크기에 따라 달라질 수 있다고 하였다. 또한 Houdayer 등 23 은 $13-30 \mathrm{~Hz}$ 의 베타파가 감각 정보의 입력증가, 감각통합 및 운동실행과 매우 밀접한 관련성을 있고, 베타대역의 변화는 입력된 감각정보의 처리과정에 대한 유용한 방법이 될 수 있다고 보고한 바 있다. 본 연구에서는 $\mathrm{FES}$ 를 해당 분절의 실제적 움직임이 유발되는 수준의 강도로 적용할 때 베타CMC가 증가하는 것으로 나타났고, 이 는 $\mathrm{CMC}$ 가 제공되고 있는 동작관찰에 의해 운동 겉질의 활동뿐만 아 니라, 근육으로부터 오는 정보의 강도에 의해 영향을 받는 다는 것을 보여주는 것으로 추측되고, 이는 효과적인 FES의 제공 강도의 신경 생리학적인 근거를 제시하는 결과라고 보여진다.

선행연구들을 살펴보면, $\mathrm{Ko}^{27}$ 는 경두개직류전류 $(\mathrm{tDCS})$ 와 말초감 각자극 또는 말초운동자극을 결합하여 반복적 움직임 훈련을 시행 한 결과, 손가락 폄근이 수축되어 관절의 완전가동범위가 유발되는 수준의 말초운동자극을 제공하였을 시에만 움직임의 반응시간이 빨라지는 유의한 차이가 나타났다고 보고하였고, Moon ${ }^{28}$ 는 FES를 통해 중추 신경 순응을 유도하기 위해서는 최대수축력의 $50 \%$ 이상을 제공하여야 한다고 보고한바 있다. 또한 Reynolds 등 29 은 운동 역치 보다 높은 강도의 전기적 자극이 겉질척수로의 흥분성을 증가시키 고 동작 상상(imagery)을 증가시킨다고 주장하였다. Houdayer 등 23 은 전기적 자극 강도에 따른 뇌활성을 비교한 연구에서 감각수준의 자 극에 비해 신경수준의 자극과 운동수준의 자극이 사건관련동기화 (event-related synchronization, ERS)를 유의하게 증가시켰다고 보고하
며, 이는 동원된 고유수용감각섬유(proprioceptive fibers)에 의한 운동 조절과 밀접한 관련을 가지고 있을 것이며, 또한 ERS가 전기적 자극 의 강도에 의한 동심성 입력의 양에 의해 영향을 받는다는 것을 보여 주는 결과라고 하였다. ${ }^{23}$

본 연구에서는 동작관찰과 동시에 제공되는 기능적 전기자극의 강도 변이에 나타나는 신경생리학적인 변화를 겉질근육코히런스를 통해 분석하였다. 그 결과 근수축으로 인해 실제적 움직임의 각도와 비슷하게 유발되는 FES강도에서 겉질근육코히런스가 유의하게 증가 하는 것으로 나타났다. 이는 제공되는 $\mathrm{FES}$ 의 강도가 대뇌와 근육 사 이의 기능적 연결에 영향을 미칠 수 있음을 보여주는 결과로써, 동작 관찰동안에 동시적으로 제공되는 $\mathrm{FES}$ 의 효과적인 강도를 제시하는 신경생리학적인 근거가 될 것이라 생각된다. 본 연구의 결과가 신경계 손상으로 인해 기능이 결여된 환자에 대한 신경재활의 임상적 기초 자료로 활용되기를 기대해본다.

\section{REFERENCES}

1. Fang Y, Daly JJ, Sun J et al. Functional corticomuscular connection during reaching is weakened following stroke. Clin Neurophysiol. 2009; 120(5):994-1002.

2. McClelland VM, Cvetkovic Z, Mills KR. Modulation of corticomuscular coherence by peripheral stimuli. Exp Brain Res. 2012;219(2):275-92.

3. Yang Q, Fang Y, Sun CK et al. Weakening of functional corticomuscular coupling during muscle fatigue. Brain Res. 2009;1250:101-12.

4. Divekar NV, John LR. Neurophysiological, behavioural and perceptual differences between wrist flexion and extension related to sensorimotor monitoring as shown by corticomuscular coherence. Clin Neurophysiol. 2013;124(1):136-47.

5. Muthukumaraswamy SD. Temporal dynamics of primary motor cortex gamma oscillation amplitude and piper corticomuscular coherence changes during motor control. Exp Brain Res. 2011;212(4):623-33.

6. Ushiyama J, Takahashi Y, Ushiba J. Muscle dependency of corticomuscular coherence in upper and lower limb muscles and training-related alterations in ballet dancers and weightlifters. J Appl Physiol. 2010;109 (4):1086-95.

7. Ushiyama J, Masakado Y, Fujiwara T et al. Contraction level-related modulation of corticomuscular coherence differs between the tibialis anterior and soleus muscles in humans. J Appl Physiol. 2012;112(8): 1258-67.

8. Schoffelen JM, Poort J, Oostenveld R et al. Selective movement preparation is subserved by selective increases in corticomuscular gamma-band coherence. J Neurosci. 2011;31(18):6750-8.

9. Clark S, Tremblay F, Ste-Marie D. Differential modulation of corticospinal excitability during observation, mental imagery and imitation of hand actions. Neuropsychologia. 2004;42(1):105-12.

10. Fogassi L, Ferrari PF, Gesierich B et al. Parietal lobe: From action organization to intention understanding. Science. 2005;308(5722):662-7.

11. Marty B, Bourguignon M, Jousmaki V et al. Cortical kinematic process- 
ing of executed and observed goal-directed hand actions. Neuroimage. 2015;119:221-8.

12. Mouthon A, Ruffieux J, Walchli M et al. Task-dependent changes of corticospinal excitability during observation and motor imagery of balance tasks. Neuroscience. 2015;303:535-43.

13. Monaghan CC, Hermens HJ, Nene AV et al. The effect of fes of the tibial nerve on physiological activation of leg muscles during gait. Med Eng Phys. 2010;32(4):332-8.

14. Popovic DB. Advances in functional electrical stimulation (fes). J Electromyogr Kinesiol. 2014;24(6):795-802.

15. Street T, Taylor P, Swain I. Effectiveness of functional electrical stimulation on walking speed, functional walking category, and clinically meaningful changes for people with multiple sclerosis. Arch Phys Med Rehabil. 2015;96(4):667-72.

16. Shendkar CV, Lenka PK, Biswas A et al. Therapeutic effects of functional electrical stimulation on gait, motor recovery, and motor cortex in stroke survivors. Hong Kong Physiother J. 2015;33(1):10-20.

17. Kim JY, Park JW, Kim SY. The effects of functional electrical stimulation combined with action observation on sensorimotor cortex. J Kor Phys Ther. 2017;29(4):164-8.

18. Park CS, Kang KY. The effects of additional action observational training for functional electrical stimulation treatment on weight bearing, stability and gait velocity of hemiplegic patients. J Phys Ther Sci. 2013;25(9): 1173-5.

19. Kim JY, Ko YM, Park JW. Comparison of eeg changes induced by action execution and action observation. J Kor Phys Ther. 2017;29(1):27-32.

20. Kuk EJ, Kim JM. An eeg-based brain mapping to determine mirror neuron system in patients with chronic stroke during action observation. J
Kor Phys Ther. 2015;27(3):135-9.

21. Kim SH, Cho JS. Action observation and cortical connectivity: Evidence from eeg analysis. J Kor Phys Ther. 2016;28(6):398-407.

22. Müller GR, Neuper C, Rupp R et al. Event-related beta eeg changes during wrist movements induced by functional electrical stimulation of forearm muscles in man. Neurosci Lett. 2003;340(2):143-7.

23. Houdayer E, Labyt E, Cassim F et al. Relationship between event-related beta synchronization and afferent inputs: Analysis of finger movement and peripheral nerve stimulations. Clin Neurophysiol. 2006;117(3):62836.

24. Hashimoto Y, Ushiba J, Kimura A et al. Correlation between eeg-emg coherence during isometric contraction and its imaginary execution. Acta Neurobiol Exp. 2010;70(1):76-85.

25. Gwin JT, Ferris DP. Beta- and gamma-range human lower limb corticomuscular coherence. Front Hum Neurosci. 2012;6:258.

26. Johnson AN, Wheaton LA, Shinohara M. Attenuation of corticomuscular coherence with additional motor or non-motor task. Clin Neurophysiol. 2011;122(2):356-63.

27. Ko AR. Effect of combined peripheral electrical stimulation and anodal transcranial direct current stimulation(tdcs) on finger movements in stroke patients. Yonsei University. Dissertation of Master's Degree. 2009.

28. Moon D. Changes of action potential of central neuron by electricalstimulation and voluntary contraction. Dongshin University. Dissertation of Master's Degree. 2006.

29. Reynolds C, Osuagwu BA, Vuckovic A. Influence of motor imagination on cortical activation during functional electrical stimulation. Clin Neurophysiol. 2015;126(7):1360-9. 